\title{
Pre-school hyperactivity/attention problems and educational outcomes in adolescence: prospective longitudinal study
}

\author{
Elizabeth Washbrook, Carol Propper and Kapil Sayal
}

\section{Background}

High levels of attentional and hyperactivity problems in school-aged children, even if subthreshold for attentiondeficit hyperactivity disorder (ADHD), are associated with academic under-achievement. Few large-scale, community-based studies have investigated the relationship between pre-school and adolescence.

\section{Aims}

To investigate whether pre-school hyperactivity/inattention and conduct problems are independently associated with academic outcomes at age 16

\section{Method}

Data from the prospective, population-based Avon Longitudinal Study of Parents and Children (ALSPAC) were used. After adjusting for a broad range of confounder variables, the associations between parent-rated hyperactivity/inattention and conduct problems measured at age 3 and academic outcomes at age 16 (national General Certificate of Secondary Education (GCSE) examination results) were investigated $(n=11640)$.

\section{Results}

Both early hyperactivity/inattention and conduct problems had negative effects on academic outcomes. In adjusted analyses, abnormal hyperactivity/inattention scores were associated with reductions of ten GCSE points in boys. Borderline and abnormal conduct problem scores were associated with reductions of $9-10$ and $12-15$ points respectively.

\section{Conclusions}

Pre-school hyperactivity/inattention and conduct problems carry risk of worse academic outcomes at 16.

\section{Declaration of interest}

None.
Children and adolescents with attention-deficit hyperactivity disorder (ADHD) have difficulties across a number of domains, including behaviour, family and peer relationships, and academic performance. ${ }^{1}$ High levels of ADHD symptoms, even if subthreshold for diagnostic criteria, also carry risk for additional difficulties. ${ }^{2-5}$ Both the underlying symptoms and associated academic under-achievement can have negative longterm consequences for occupational functioning, employment status and economic productivity. ${ }^{6,7}$ Although the diagnosis of ADHD in children tends to be more reliable in school-aged children, hyperactivity and inattention problems are present from pre-school age. ${ }^{8}$ A systematic review highlighted that prospective investigations of the relationship between early hyperactivity/ inattention and later academic outcomes should take account of confounders within three key domains. ${ }^{9}$ First, comorbid disorders may affect academic performance. Second, family factors such as socioeconomic status and parental education and mental health problems may confound the association between ADHD symptoms and academic outcomes. Third, child IQ is associated with academic performance and children with ADHD or hyperactivity/inattention problems tend to have lower IQ scores than children without these difficulties. ${ }^{10}$ Other reviews of the relationship between ADHD-type problems and academic outcomes $^{11,12}$ highlight the potential limitations of selection bias involving clinically referred samples or children who meet criteria for ADHD (i.e. have functional impairment) and of measurement bias involving teacher ratings as predictors as these might be influenced by children's academic progress and attainments. To address these issues, we use a large community-based birth cohort to investigate the independent contribution of two common types of early childhood behaviour problems (hyperactivity/inattention and conduct problem symptoms) on nationally assessed academic performance at age 16.

\section{Method}

\section{Sample}

The Avon Longitudinal Study of Parents and Children (ALSPAC) is a large prospective birth cohort study in South West England; study design and methods are described in detail elsewhere (including www.bristol.ac.uk/alspac). ${ }^{13}$ Pregnant women $(n=14541)$ with an expected date of delivery between April 1991 and December 1992 were enrolled. Parents and children in ALSPAC have been followed up regularly through questionnaires self-administered to the mothers, the children and their teachers, through individual face-to-face assessments and linkage to selected external data. The ALSPAC sample is representative of a White population with diverse socioeconomic backgrounds similar to both the UK overall and the local population of mothers with infants. The sample includes a small (5\%) proportion of participants from Black and minority ethnic backgrounds. A total of 13988 study children were alive at 1 year of age. Ethical approval for the study was obtained from the ALSPAC Ethics and Law Committee and the local research ethics committees.

Child participants' records were matched to the National Pupil Database (NPD), the central repository for pupil-level educational data in England. Data on General Certificate of Secondary Education (GCSE) examination results at roughly age 16 years, the key outcome of interest, were available for all pupils attending publicly funded state schools (children schooled at home or attending independent schools or schools outside England were 
not eligible for our sample). Information on GCSE attainment from the NPD was available on 11640 children $(83 \%$ of the core ALSPAC sample).

\section{Measures}

\section{Predictor variables}

Pre-school hyperactivity/inattention and conduct problems were assessed using the parent-completed Strengths and Difficulties Questionnaire (SDQ) at the age of 47 months. ${ }^{14}$ This widely used dimensional measure of childhood mental health has been validated in a large, nationally representative, community sample. ${ }^{15}$ The SDQ has five subscales relating to hyperactivity/ inattention, conduct problems, emotional problems, peer relationships and prosocial behaviours. Five items each relate to hyperactivity/inattention and conduct problems, with higher scores (scale of $0-10$ ) indicating greater levels of severity. Based on recommended cut-offs, ${ }^{14}$ the hyperactivity/inattention subscale was recoded to normal (score of 0-5), borderline (6) and abnormal (7-10) and the conduct problems subscale recoded to normal (score 0-2), borderline (3), abnormal (4-10).

\section{Academic outcome variables}

Academic outcomes were assessed using results from externally marked GCSE examinations typically taken in the academic year during which pupils turn 16 years of age ( $99 \%$ of our sample were aged 15 years at the start of the relevant academic year). The GCSE examinations are important as they are the principal means of assessing pupil attainment at the end of compulsory secondary education and provide an objective 'real-world' measure of academic performance. Pupils study up to 12 subjects ( 8 on average) for GCSE, some of which (e.g. English and Maths) are compulsory as part of the National Curriculum. The subjects are graded individually on a scale of $A^{*}$ (highest) to $\mathrm{G}$ (lowest). Universities and employers usually regard $\mathrm{A}^{*} \mathrm{C}$ as pass grades.

The data from GCSE results were treated in two ways.

(a) Continuous scores reflecting capped total points summed over the eight best GCSE grades achieved. This involves a minimum of 16 points for a $G$ grade with an additional 6 points per each grade increase - resulting in a maximum of 58 points for an $\mathrm{A}^{\star}$ grade. ${ }^{16}$ This capped total point score avoids conflating the number of GCSEs taken and the grades achieved. This continuous measure enables analysis of effects across the full distribution of pupil ability.

(b) A binary outcome (yes/no) reflecting whether the pupil obtained at least five $\mathrm{A}^{*}-\mathrm{C}$ grade GCSEs including English and Maths. This minimum is important for pupil progression into post-compulsory education. It is also used as a key performance indicator for schools by the Department for Education in England and is published in school league tables that allow parents and others to compare school performance.

\section{Confounder variables}

The analyses adjusted for a number of factors that potentially confound the relationship between hyperactivity/inattention or conduct problems and academic performance. Child factors included gender and total IQ score, assessed at the age of 8 years using the Weschler Intelligence Scale for Children-III (WISC-III). ${ }^{17}$

Parental sociodemographic indicators were collected from self-completed questionnaires during the pregnancy. These included the highest social class of either parent (based on the Registrar General's classification of occupations into six categories: I (professional), II (managerial and technical), IIIa (skilled manual), IIIb (skilled non-manual), IV (semi-skilled) and $\mathrm{V}$ (unskilled) $)^{18}$ and highest level of parental educational attainment (split into five categories: Certificate of Secondary Education (CSE) or less, vocational qualification, O-level (the predecessor to the GCSE), A-level or equivalent (examinations taken at 18 years of age after 2 years of post-compulsory education), and university degree or equivalent).

As the parental SDQ was usually completed by the mother and maternal mental health problems may influence how they rate their child's behaviour, ${ }^{19}$ maternal mental health measures available in ALSPAC were used. The well-validated Edinburgh Postnatal Depression Scale (EPDS) ${ }^{20,21}$ was completed by mothers at 18 and 32 weeks gestation (pregnancy), 8 weeks and 8,21 and 33 months post-birth. The average of these EPDS scores was used in the analyses.

\section{Analysis}

The analyses involved the following stages.

\section{Stage 1}

Linear regression analyses were used to examine the proportion of variance in the total capped GCSE point score that could be explained individually, and then in combination, by the following factors: hyperactivity/inattention, conduct problems, child IQ, gender, parental education and social class, and early maternal depression.

\section{Stage 2}

Gender-specific multivariable linear regression analyses were used to assess the predictive role of borderline and abnormal hyperactivity/inattention scores on capped GCSE points after adjusting for confounder variables. These analyses inform about any gradient effects of increasing levels of hyperactivity/inattention on GCSE points. Gender-specific analyses were undertaken because there are gender differences in hyperactivity/inattention scores and capped GCSE point scores (Table 1).

Assessment was also made for interactions between hyperactivity/inattention and conduct problems. The predictor and confounder variables were introduced sequentially in three steps and then all simultaneously: step 1 - conduct problems; step 2 - parental sociodemographic factors (highest social class of either parent, highest level of maternal education and highest level of paternal education) and maternal depression; step 3 - child IQ. Although IQ is a potential confounder, it is possible that there is over-adjustment in the final model. As IQ is measured at the age of 8 years, IQ scores may be on the causal pathway between behaviour problems and GCSE grades. That is, early behavioural difficulties might have a negative impact on children's learning which is reflected in IQ scores (measured at age 8 years) and therefore have direct or indirect influences on academic performance. If IQ differences were entirely 'caused' by behaviour, then the specification in the model in step 2 is the appropriate interpretation for inferring the effects of behaviour problems on GCSE grades. However, if IQ is purely a confounder, so that it is determined independently of early behaviour problems, then the final model (step 3) is the correct one. As the actual effect is likely to lie somewhere between the two, findings from both models are presented to give an indication of the upper and lower bounds of effects.

\section{Stage 3}

Gender-specific multivariable logistic regression analyses were carried out to assess the predictive roles of abnormal hyperactivity/ inattention and conduct problem scores on the achievement of 
five $A^{*}-C$ grades. These analyses inform whether severe levels of early behaviour problems predict failure to achieve minimum school-leaving qualifications. Predictor and confounder variables were simultaneously entered into a multivariable logistic regression model to provide adjusted odds ratio (OR) estimates. As in stage 2, assessment was made for interactions between hyperactivity/inattention and conduct problems and the analyses were run with and without IQ scores to provide an indication of the upper and lower bounds of effects.

\section{Multiple imputation model}

Although the matching of the ALSPAC database to the administrative NPD means that educational outcome variables are available for 11640 children, missing data on the SDQ predictor variables and other covariates leave only 3934 cases (34\%) with complete data. To exploit all the information contained in the sample we used multiple imputation by chained equations. ${ }^{22}$ We ran five multiple imputations, separately for girls and boys, using the Stata command ice (Stata version 12.1 for Windows). Estimates were combined by using Rubin's rules through the command mim (see Royston ${ }^{23}$ ). This multiple imputation method relies on the assumption that data are missing at random, given the known characteristics of the missing individuals. ${ }^{24}$ We used 65 variables in the imputation model, including those in the principal analyses plus additional ALSPAC variables obtained from different sources. These included all five SDQ subscale scores obtained on eight separate occasions from either the parent or teacher between the ages of 3 and 13 years, receipt of free school meals and special educational needs status (from the NPD), academic achievement outcomes from Key Stage national tests taken at ages 7,11 and 14 years, birth weight and mother's age. The inclusion of this large set of additional variables, many of which are strongly correlated with the measures of interest and have high response rates, allowed us to examine to what extent missing data were affecting the results. Estimates were also undertaken for all participants who had complete data (complete case analyses) to allow for sensitivity analyses.

\section{Results}

Descriptive statistics (Table 1) show that boys achieved fewer capped GCSE points and were less likely to obtain the minimum expected five $A^{*}-C$ grade GCSEs. More boys had borderline or abnormal hyperactivity/inattention scores but there was less gender variation in the conduct problems score.

\section{Variation in GCSE points}

The proportion of the variance in total GCSE points score explained by the following individual factors was: hyperactivity/ inattention (3\%), conduct problems (3\%), child IQ (37\%), gender

\begin{tabular}{|c|c|c|c|c|}
\hline & $\begin{array}{l}\text { Whole sample } \\
\quad(n=11640)\end{array}$ & $\begin{array}{c}\text { Boys } \\
(n=5917)\end{array}$ & $\begin{array}{c}\text { Girls } \\
(n=5723)\end{array}$ & $\begin{array}{l}\text { Gender } \\
\text { difference } \\
\quad P\end{array}$ \\
\hline Female, \% & 49 & - & - & - \\
\hline Capped GCSE points, ${ }^{\mathrm{b}}$ mean (s.d.) & $315.82(96.20)$ & $303.87(99.3)$ & $328.18(91.3)$ & $<0.001$ \\
\hline Failed to get $5 A^{*}-C$ GCSEs including English and Maths, \% & 49 & 54 & 44 & $<0.001$ \\
\hline \multicolumn{5}{|l|}{ Hyperactivity/inattention at 47 months, \% } \\
\hline Normal & 74 & 70 & 78 & $<0.001$ \\
\hline Borderline & 11 & 12 & 10 & 0.001 \\
\hline Abnormal & 15 & 19 & 12 & $<0.001$ \\
\hline \multicolumn{5}{|l|}{ Conduct problems at 47 months, \% } \\
\hline Normal & 66 & 65 & 68 & 0.036 \\
\hline Borderline & 20 & 20 & 19 & 0.640 \\
\hline Abnormal & 14 & 15 & 13 & 0.006 \\
\hline \multicolumn{5}{|l|}{ Mother's highest qualification, \% } \\
\hline CSE/none & 23 & 23 & 23 & 0.849 \\
\hline Vocational & 11 & 11 & 10 & 0.721 \\
\hline O-level & 35 & 35 & 36 & 0.783 \\
\hline A-level & 21 & 21 & 21 & 0.902 \\
\hline Degree & 10 & 10 & 10 & 0.715 \\
\hline \multicolumn{5}{|l|}{ Father's highest qualification, \% } \\
\hline CSE/none & 28 & 28 & 28 & 0.915 \\
\hline Vocational & 10 & 10 & 9 & 0.418 \\
\hline O-level & 22 & 22 & 22 & 0.842 \\
\hline A-level & 26 & 25 & 27 & 0.067 \\
\hline Degree & 14 & 15 & 14 & 0.127 \\
\hline \multicolumn{5}{|l|}{ Social class (highest of either parent), \% } \\
\hline I. Professional & 11 & 11 & 10 & 0.233 \\
\hline II. Managerial/technical & 38 & 39 & 38 & 0.625 \\
\hline Illa. Skilled non-manual & 29 & 30 & 28 & 0.195 \\
\hline IIIb. Skilled manual & 15 & 14 & 15 & 0.152 \\
\hline IV. Semi-skilled & 6 & 5 & 7 & 0.097 \\
\hline V. Unskilled & 2 & 2 & 2 & 0.844 \\
\hline WISC IQ at 8 years, mean (s.d.) & $99.7(17.7)$ & $99.7(18.3)$ & $99.7(17.0)$ & 0.871 \\
\hline Average maternal EPDS, ${ }^{c}$ mean (s.d.) & $6.25(3.80)$ & $6.26(3.82)$ & $6.25(3.77)$ & 0.930 \\
\hline \multicolumn{5}{|c|}{$\begin{array}{l}\text { CSE, Certificate of Secondary Education; EPDS, Edinburgh Postnatal Depression Scale; GCSE, General certificate of Secondary Education; WISC, Weschler Intelligence Scale for Children } \\
\text { a. Means and standard deviations calculated over five complete imputed data-sets and combined using Rubin's rules. } \\
\text { b. Capped GCSE points are the sum over the } 8 \text { best GCSE grades, scored } 6 \text { points per each grade increase (from } G=16 \text { to } A^{*}=58 \text { ). } \\
\text { c. Average of scores at } 18 \text { and } 32 \text { weeks gestation (pregnancy), and } 8 \text { weeks and } 8,21 \text { and } 33 \text { months post-birth. }\end{array}$} \\
\hline
\end{tabular}


(2\%), parental education and social class (24\%) and early maternal depression (2\%). After adjusting for child gender and IQ, parental education and social class and early maternal depression (these variables collectively accounting for $45 \%$ of the variance), hyperactivity and conduct problem ratings made an additional contribution of $0.5 \%$ of the variance.

\section{Roles of borderline and abnormal hyperactivity/ inattention and conduct problems scores in predicting GCSE points}

Table 2 shows the adjusted regression coefficients for hyperactivity/inattention and conduct problems in boys and girls with successively greater levels of adjustments made to the model. For boys, the unconditional model (first column) shows that boys with borderline hyperactivity/inattention scores at 47 months scored 29 fewer points (five GCSE grades) and boys with abnormal hyperactivity/inattention scores scored 42 fewer points (equivalent to seven GCSE grades) on average than boys with normal hyperactivity/inattention scores. Adjustment for conduct problems reduced these differences to 23 and 31 points respectively (column 2), providing evidence of confounding. The effects of hyperactivity/inattention and conduct problems with no further controls were of similar magnitude and were additive, with no evidence of interaction effects. The coefficients were substantially reduced after adjusting for parental sociodemographic factors and maternal depression (column 3). These estimates suggest a 12- to 13-point penalty to borderline problems of either type (about two GCSE grades), a 17-point penalty to abnormal conduct problems and a 21-point penalty to abnormal hyperactivity/inattention. Further adjustment for child IQ (column 4) explained a large proportion of the GCSE differences associated with hyperactivity/inattention (over 50\%) but much less of the differences associated with conduct problems. This implies that IQ is more strongly associated with hyperactivity/ inattention than conduct problems. If IQ is treated as a pure confounder, the estimates imply 6- and 10-point (1.67 of a GCSE grade) deficits associated with borderline and abnormal hyperactivity/inattention scores respectively. The effects of conduct problems in the final model remained larger and were 10 and 15 points for borderline and abnormal scores respectively.

For girls, similar overall patterns were evident, although the effects of abnormal hyperactivity/inattention scores were of a smaller magnitude (4-point penalty) than for boys. The effects of conduct problems for girls were more comparable to boys and associations remained (at 9 and 12 points for borderline and abnormal scores respectively) after adjustment was made for IQ.

Estimates from sensitivity analyses involving fully adjusted models from the complete case analyses gave a coefficient for abnormal hyperactivity/inattention scores that was of a similar magnitude in boys $(-11.96)$ and slightly larger in girls (-7.76).

These effects were smaller than those of other characteristics in the fully adjusted models, for example, larger differences were associated with the lowest level of maternal education relative to the highest level ( 32 and 29 points in boys and girls respectively), the lowest level of paternal education relative to the highest level (32 and 33 points), the lowest level of parental social class relative to the highest level (58 and 48 points), and a 10-point increment in the IQ score ( 26 and 27 points).

\section{Roles of abnormal hyperactivity/inattention and conduct problems in predicting achievement of five $A^{*}-C$ grades}

In terms of categorical predictions, logistic regressions analyses (Table 3) indicated that abnormal hyperactivity/inattention (in boys) and conduct problems predicted failure to achieve five good GCSEs, after adjusting for child IQ, maternal and paternal education, parental social class and early maternal depression. There was no evidence of interaction effects between the two types of problem. In sensitivity analyses involving complete case estimates, the effect for abnormal hyperactivity/inattention in boys was larger (adjusted $\mathrm{OR}=1.64 ;$ 95\% CI 1.21-2.22; $P=0.001)$ but there remained no association among girls (adjusted OR $=1.14 ; 95 \%$ CI $0.79-1.67 ; P=0.485$ ).

\section{Discussion}

Our findings highlight that, after adjusting for a range of key confounding variables, behavioural problems present at the age of 3 years have an impact on academic attainment at the age of 16 years. Adverse effects were apparent in both boys and girls, whether assessed using continuous or categorical outcomes. For boys, both hyperactivity/inattention and conduct problems were independently associated with worse academic outcomes. In contrast, early conduct problems rather than hyperactivity/ inattention were important in girls. This might reflect reduced power to assess the impact of abnormal hyperactivity/inattention in girls as the SDQ cut-offs are not gender-specific.

As expected, other factors were also important, with child IQ and parental education and social class having major effects on

\begin{tabular}{|c|c|c|c|c|c|c|c|c|}
\hline & \multicolumn{4}{|c|}{ Boys $(n=5917)$} & \multicolumn{4}{|c|}{ Girls $(n=5723)$} \\
\hline & $\begin{array}{l}\text { Unadjusted } \\
\text { coefficients } \\
\text { (s.e.) }\end{array}$ & $\begin{array}{l}\text { Partially } \\
\text { adjusted } \\
\text { coefficients } \\
\text { (s.e. })^{\mathrm{b}}\end{array}$ & $\begin{array}{l}\text { Adjusted } \\
\text { coefficients } \\
\text { without IQ } \\
(\text { s.e. })^{c}\end{array}$ & $\begin{array}{c}\text { Fully } \\
\text { adjusted } \\
\text { coefficients } \\
\text { (s.e. })^{\text {d }}\end{array}$ & $\begin{array}{l}\text { Unadjusted } \\
\text { coefficients } \\
\text { (s.e.) }\end{array}$ & $\begin{array}{c}\text { Partially } \\
\text { adjusted } \\
\text { coefficients } \\
\text { (s.e. })^{\mathrm{b}}\end{array}$ & $\begin{array}{l}\text { Adjusted } \\
\text { coefficients } \\
\text { without IQ } \\
\text { (s.e.) })^{c}\end{array}$ & $\begin{array}{c}\text { Fully } \\
\text { adjusted } \\
\text { coefficients } \\
{\text { (s.e. })^{\text {d }}}^{\text {a }}\end{array}$ \\
\hline Borderline hyperactivity/inattention & $-29.13^{*}(5.97)$ & $-22.98 *(5.46)$ & $-13.31 *(4.98)$ & $-5.85(3.78)$ & $-23.68^{*}(5.44)$ & $-17.88 *(5.75)$ & $-6.79(4.91)$ & $-2.46(3.74)$ \\
\hline Abnormal hyperactivity/inattention & $-42.10 *(5.03)$ & $-31.12 *(4.87)$ & $-20.90 *(3.38)$ & $-10.01 *(3.04)$ & $-37.18 *(3.99)$ & $-27.03 *(4.70)$ & $-14.42^{*}(4.36)$ & $-4.04(4.15)$ \\
\hline Borderline conduct problems & - & $-22.44^{*}(4.69)$ & $-12.08 *(3.34)$ & $-10.14^{*}(3.34)$ & - & $-20.82^{*}(5.08)$ & $-12.58 *(3.60)$ & $-9.48^{*}(3.15)$ \\
\hline Abnormal conduct problems & - & $-29.71 *(5.55)$ & $-16.94 *(4.71)$ & $-15.23^{*}(3.63)$ & - & $-28.08 *(6.63)$ & $-17.97 *(6.25)$ & $-11.51 *(4.19)$ \\
\hline$R^{2}$ & 0.032 & 0.047 & 0.277 & 0.465 & 0.024 & 0.034 & 0.258 & 0.433 \\
\hline \multicolumn{9}{|c|}{$\begin{array}{l}\text { GCSE, General Certificate of Secondary Education. } \\
\text { a. Combined estimates from five multiply imputed data-sets. } \\
\text { b. Mutually adjusted for hyperactivity/inattention and conduct problems. } \\
\text { C. Additionally adjusted for parental education and social class and early maternal depression. } \\
\text { d. Additionally adjusted for child IQ. } \\
{ }^{*} P<0.01 \text {. }\end{array}$} \\
\hline
\end{tabular}




\begin{tabular}{|c|c|c|c|c|c|c|c|c|}
\hline \multirow[b]{2}{*}{ Predictor } & \multicolumn{4}{|c|}{ Boys } & \multicolumn{4}{|c|}{ Girls } \\
\hline & $\begin{array}{l}\text { Adjusted OR } \\
(95 \% \mathrm{Cl})^{\mathrm{b}}\end{array}$ & $P$ & $\begin{array}{l}\text { Adjusted OR } \\
(95 \% \mathrm{Cl})^{\mathrm{c}}\end{array}$ & $P$ & $\begin{array}{c}\text { Adjusted OR } \\
(95 \% \mathrm{Cl})^{\mathrm{b}}\end{array}$ & $P$ & $\begin{array}{l}\text { Adjusted OR } \\
(95 \% \mathrm{Cl})^{\mathrm{c}}\end{array}$ & $P$ \\
\hline Abnormal hyperactivity/inattention ${ }^{d}$ & $1.57(1.32-1.87)$ & $<0.001$ & $1.33(1.09-1.62)$ & 0.004 & $1.47(1.20-1.80)$ & $<0.001$ & $1.24(0.98-1.56)$ & 0.074 \\
\hline Abnormal conduct problems ${ }^{\mathrm{d}}$ & $1.39(1.13-1.70)$ & 0.002 & $1.40(1.14-1.72)$ & 0.003 & $1.46(1.09-1.96)$ & 0.011 & $1.32(1.01-1.73)$ & 0.044 \\
\hline Child IQ & & & $0.54(0.51-0.58)$ & $<0.001$ & & & $0.47(0.44-0.49)$ & $<0.001$ \\
\hline Maternal education ${ }^{f}$ & $3.37(2.48-4.58)$ & $<0.001$ & $1.63(1.18-2.24)$ & 0.003 & $5.14(3.68-7.18)$ & $<0.001$ & $2.90(2.01-4.17)$ & $<0.001$ \\
\hline Paternal education ${ }^{f}$ & $3.58(2.72-4.71)$ & $<0.001$ & $2.35(1.73-3.18)$ & $<0.001$ & $3.20(2.35-4.35)$ & $<0.001$ & $1.97(1.45-2.68)$ & $<0.001$ \\
\hline Parental social class ${ }^{f}$ & $3.36(1.49-7.55)$ & 0.003 & $3.38(1.36-8.40)$ & 0.011 & $4.33(1.76-10.65)$ & 0.001 & $3.93(1.74-8.85)$ & 0.001 \\
\hline Maternal depression (EPDS mean) & $1.01(0.99-1.02)$ & 0.530 & $0.99(0.97-1.01)$ & 0.272 & $1.04(1.02-1.07)$ & $<0.001$ & $1.04(1.02-1.06)$ & 0.001 \\
\hline
\end{tabular}

examination scores. In terms of relative comparisons, for example, the effect of abnormal hyperactivity/inattention scores on boys' GCSE points (10 points) is similar in magnitude to the effect of having an IQ reduction of around 4 points. Although the individual contributions made by the hyperactivity and conduct problem ratings to the variance in the capped GCSE points were small, there was a gradient effect on GCSE points as symptom severity increased. When considered categorically, high levels of early hyperactivity/inattention were associated with a 33\% increase in boys' failure to achieve five good GCSE grades, including English and Maths. There was an effect of similar magnitude for early conduct problems among both genders.

To our knowledge, this is the largest follow-up study of the relationship between pre-school hyperactivity/inattention and conduct problems and later academic performance with a follow-up period of over 10 years. ${ }^{9}$ By demonstrating that, after adjusting for key confounders, both early hyperactivity/ inattention and conduct problem ratings obtained at the age of 3 years had independent additional effects on exam performance at the age of 16 years, we extend the findings from studies by Breslau et al (follow-up from ages 6 to 17 years) and Duncan et al investigating 4- to 6-year-olds (follow-up duration of 4-10 years). ${ }^{25,26}$

As well as confirming findings from other studies with either smaller sample sizes or shorter durations of follow-up that used a range of sampling approaches (clinical and/or community-based studies using ADHD diagnostic criteria or community-based studies using teacher and/or parent ratings), ${ }^{3,27-30}$ we also found that conduct problems play an important role, especially in girls. Although comorbid hyperactivity/inattention is regarded as confounding the relationship between early conduct problems and academic performance, ${ }^{31,32}$ a cohort study that used parentreported predictors and academic outcomes suggested that both hyperactivity/inattention and symptoms of conduct disorder (but not oppositional-defiant symptoms) predicted poor outcomes. ${ }^{33}$ Given that high levels of conduct problems are associated with adverse educational outcomes and costs, ${ }^{34}$ the potential independent contribution of these problems should not be overlooked.

\section{Methodological issues}

The strengths of our study include the use of a representative community sample, large sample size, long period of follow-up, investigation of the roles of two different types of behavioural difficulties measured in the pre-school period, adjustment for key confounders and the utilisation of a real-world outcome measure of academic attainment (i.e. results from crucial examinations which determine future education and employment trajectory and opportunities). Many other studies have only used academic tests that focus on specific domains of learning such as reading, mathematics, spelling and vocabulary. ${ }^{11}$ The large sample size enabled a robust investigation of the relative effects by gender, which is important given that hyperactivity/inattention problems are more prevalent in males and adolescent academic performance tends to be better in females. Information was available about participants who withdrew from the study in order to inform about possible selection bias. Although previous data from ALSPAC suggest that withdrawal was systematic, this does not influence associations of risk of behavioural disorders. ${ }^{35}$ Many previous studies have used clinically referred samples which may be prone to confounding from severity of disorder and the presence and severity of comorbid disorders.

We note the following limitations. First, the SDQ hyperactivity/ inattention scale did not allow for hyperactivity/impulsivity and inattention domains to be investigated separately. Some studies suggest that inattentiveness is a stronger predictor than hyperactivity of later academic difficulties. ${ }^{9,36,37}$ Second, although the analyses adjusted for IQ at age 8 years, we have no information about mediating factors. When added to the model, IQ was the variable that most reduced the magnitude of effects of early behaviour problems. This was a stringent specification and through over-adjustment may have resulted in underestimation of the effect on educational achievement, particularly if early behaviour problems interfere with learning ability which then has an impact on GCSE performance. Third, school factors including school selection policies and quality of teaching may also influence academic outcomes. Fourth, although we adjusted for maternal mental health, other factors such as the quality of attachment might also play a role in influencing parental ratings of behaviour and later academic outcome. Fifth, it is possible that some participants received a clinical diagnosis or interventions for this which might have ameliorated their outcomes. However, at the time of the study in the UK, few children with ADHD received a clinical diagnosis or medication. ${ }^{38}$ Finally, we did not have information about specific cognitive domains or executive functioning skills. Hyperactivity/inattention may also have an impact on specific scholastic skills (e.g. reading, maths) which, in turn, affect outcome. A follow-up of 21 pre-schoolers with pervasive hyperactivity highlighted an association with reading difficulties at age 15 years $^{39}$ and a meta-analysis, including 
cross-sectional studies, suggests that the greatest academic impact of ADHD is on reading assessments. ${ }^{11}$ Alternatively, executive function deficits, reflecting difficulties with working memory or response inhibition, may mediate the relationship between ADHD and academic problems. This may particularly be the case if both inattention and executive function problems are present and may partially explain possible mechanisms of effects. ${ }^{40}$

\section{Practice and research implications}

Although the effect size of hyperactivity/inattention on later academic performance was small at the individual level, the overall magnitude of the impact is likely to be significant when considering population-level educational and economic perspectives. These findings raise questions about early identification and appropriate interventions. There is a strong argument for the early identification of behavioural problems as these problems affect developmental trajectories and carry long-term risk into adolescence and adulthood. However, to be useful, early identification and intervention need to be linked. Furthermore, the optimal approach to early identification remains unclear. Although there is little evidence for benefits associated with routine screening for ADHD-type problems in the early school years, teachers are well placed to identify young children with high levels of behavioural problems. ${ }^{5}$

In terms of practice implications, our findings have also highlighted that early conduct problems (reflecting oppositional and defiant behaviours in this age group) in both genders are independently associated with worse academic outcomes in adolescence. Given this, teachers should be encouraged to enhance their awareness of the long-term implications of early behavioural difficulties, particularly for children they might regard as being at risk, and to take parental concerns about behaviour problems seriously. This is important as teachers are a key point of contact for parents with concerns. ${ }^{38}$ At school-entry, enquiries could be made about parental concerns regarding the child's behaviour. If parents or teachers have concerns, further assessment on specific behavioural problems may then enable access to evidence-based interventions that help to reduce symptoms. For example, clinical practice guidelines recommend the use of parent-based programmes using behavioural management approaches for early behaviour problems even if this is at a pre-diagnostic stage. ${ }^{1}$

From a clinical perspective, clinicians should inform the parents and teachers of young children with high levels of hyperactivity/ inattention and conduct problems about the long-term academic risks so that individual-level educational interventions can be offered at school. Appropriate early academic support for the child might help to reduce long-term risk. Although our findings highlight the effect of early problems, suggesting that interventions when children are young may help in ameliorating the potential impact of these difficulties, randomised controlled trial methodologies are required to determine whether early identification approaches are cost-effective in improving outcomes.

\section{Elizabeth Washbrook, PhD, Centre for Multilevel Modelling, University of Bristol; Carol Propper, PhD, Department of Economics, University of Bristol; Kapil Sayal, MRCPsych, PhD, Division of Psychiatry and Institute of Mental Health, University of Nottingham, UK}

Correspondence: Kapil Sayal, Division of Psychiatry, University of Nottingham, E Floor, South Block, Queen's Medical Centre, Nottingham NG7 2UH, UK. Email: kapil.sayal@nottingham.ac.uk

First received 30 Nov 2012, final revision 17 May 2013, accepted 10 Jun 2013

\section{Funding}

This research was specifically funded by the Economic and Social Research Council Grant Number RES-060-23-0011: Impact of Family Socio-economic Status on Outcomes in Childhood and Adolescence.

\section{Acknowledgements}

We are extremely grateful to all the families who took part in this study, the midwives for their help in recruiting them, and the whole ALSPAC team, which includes interviewers, computer and laboratory technicians, clerical workers, research scientists, volunteers, managers, receptionists and nurses. The UK Medical Research Council and the Wellcome Trust (grant ref: 092731) and the University of Bristol provide core support for ALSPAC. This publication is the work of the authors who will serve as guarantors for the contents of this paper. We also thank Professor David Daley for his helpful comments on the manuscript.

\section{References}

1 National Institute for Health and Clinical Excellence. Attention Deficit Hyperactivity Disorder: Diagnosis and Management of ADHD in Children Young People, and Adults (Clinical Guideline CG72). NICE, 2008.

2 Taylor E, Chadwick O, Heptinstall E, Danckaerts M. Hyperactivity and conduct problems as risk factors for adolescent development. J Am Acad Child Adolesc Psychiatry 1996; 35: 1213-26.

3 Fergusson DM, Lynskey MT, Horwood LJ. Attentional difficulties in middle childhood and psychosocial outcomes in young adulthood. J Child Psychol Psychiatry 1997; 38: 633-44.

4 Willoughby MT. Developmental course of ADHD symptomatology during the transition from childhood to adolescence: a review with recommendations. J Child Psychol Psychiatry 2003; 44: 88-106.

5 Sayal K, Owen V, White K, Merrell C, Tymms P, Taylor E. Impact of early school-based screening and intervention programs for ADHD on children's outcomes and access to services follow-up of a school-based trial at age 10 years. Arch Pediatr Adolesc Med 2010; 164: 462-9.

6 Mannuzza S, Klein RG, Bessler A, Malloy P, Hynes ME. Educational and occupational outcome of hyperactive boys grown up. J Am Acad Child Adolesc Psychiatry. 1997; 36: 1222-7.

7 Biederman J, Monuteaux M, Mick E, Spencer T, Wilens T, Silva J, et al. Young adult outcome of attention deficit hyperactivity disorder: a controlled 10-year follow-up study. Psychol Med 2008; 39: 167-79.

8 Sonuga-Barke EJ, Auerbach J, Campbell SB, Daley D, Thompson M. Varieties of preschool hyperactivity: multiple pathways from risk to disorder. Dev Sci 2005; 8: 141-50

9 Polderman TJ, Boomsma DI, Bartels M, Verhulst FC, Huizink AC. A systematic review of prospective studies on attention problems and academic achievement. Acta Psychiatr Scand 2010; 122: 271-84.

10 Frazier TW, Demaree HA, Youngstrom EA. Meta-analysis of intellectual and neuropsychological test performance in attention-deficit/hyperactivity disorder. Neuropsychology 2004; 18: 543-55.

11 Frazier TW, Youngstrom EA, Glutting JJ, Watkins MW. ADHD and achievement: meta-analysis of the child, adolescent, and adult literatures and a concomitant study with college students. J Learn Disabil 2007; 40: 49-65.

12 Loe IM, Feldman HM. Academic and educational outcomes of children with ADHD. J Pediatr Psychol 2007; 32: 643-54.

13 Boyd A, Golding J, Macleod J, Lawlor DA, Fraser A, Henderson J, et al. Cohort Profile: the 'children of the $90 \mathrm{~s}^{\prime}$ - the index offspring of the Avon Longitudinal Study of Parents and Children. Int J Epidemiol 2013; 42: 111-27.

14 Goodman R. The Strengths and Difficulties Questionnaire: a research note. J Child Psychol Psychiatry 1997; 38: 581-6.

15 Goodman R. Psychometric properties of the strengths and difficulties questionnaire. J Am Acad Child Adolesc Psychiatry 2001; 40: 1337-45.

16 Department for Education. Test and examination point scores used in the 2008 achievement and attainment tables and calculation of KS4 capped point score. 2008. Available at: http://www.education.gov.uk/performancetables/ schools_08/testandexam_pointscores08.doc (accessed 12 Jun 2013).

17 Wechsler D, Golombok S, Rust J. Wechsler Intelligence Scale for Children Third Edition UK Manual (WISC-III UK). Psychological Corporation, 1992.

18 office for National Statistics. Standard Occupational Classification. HMSO, 1991.

19 Sayal K, Taylor E. Parent ratings of school behaviour in children at risk of attention deficit/hyperactivity disorder. Acta Psychiatr Scand 2005; 111: $460-5$.

20 Cox JL, Holden JM, Sagovsky R. Detection of postnatal depression. Development of the 10-item Edinburgh Postnatal Depression Scale. Br J Psychiatry 1987; 150: 782-6.

21 Murray L, Carothers AD. The validation of the Edinburgh Post-natal Depression Scale on a community sample. Br J Psychiatry 1990; 157: 288-90. 
22 van Buuren S, Boshuizen HC, Knook DL. Multiple imputation of missing blood pressure covariates in survival analysis. Stat Med 1999; 18: 681-94.

23 Royston P. Multiple imputation of missing values. Stata J 2004; 4: 227-41.

24 Sterne JA, White IR, Carlin JB, Spratt M, Royston P, Kenward MG, et al. Multiple imputation for missing data in epidemiological and clinical research: potential and pitfalls. BMJ 2009; 338: b2393.

25 Breslau J, Miller E, Breslau N, Bohnert K, Lucia V, Schweitzer J. The impact of early behavior disturbances on academic achievement in high school. Pediatrics 2009; 123: 1472-6.

26 Duncan GJ, Dowsett CJ, Claessens A, Magnuson K, Huston AC, Kiebanov P, et al. School readiness and later achievement. Dev Psychol 2007; 43: 1428-46.

27 Fischer M, Barkley RA, Edelbrock CS, Smallish L. The adolescent outcome of hyperactive children diagnosed by research criteria: II. Academic, attentional and neuropsychological status. J Consult Clin Psychol 1990; 58: 580-8.

28 Massetti GM, Lahey BB, Pelham WE, Loney J, Ehrhardt A, Lee SS, et al. Academic achievement over 8 years among children who met modified criteria for attention-deficit/hyperactivity disorder at 4-6 years of age. J Abnorm Child Psychol 2008; 36: 399-410.

29 Barbaresi WJ, Katusic SK, Colligan RC, Weaver AL, Jacobsen SJ. Long-term school outcomes for children with attention-deficit/hyperactivity disorder: a population-based perspective. J Dev Behav Pediatr 2007; 28: 265-73.

30 Merrell C, Tymms PB. Inattention, hyperactivity and impulsiveness: their impact on academic achievement and progress. Br J Educ Psychol 2001; 71 43-56.

31 Fergusson DM, Horwood LJ, Lynskey MT. The effects of conduct disorder and attention deficit in middle childhood on offending and scholastic ability at age 13. J Child Psychol Psychiatry 1993; 34: 899-916.
32 Daley D, Birchwood J. ADHD and academic performance: why does ADHD impact on academic performance and what can be done to support ADHD children in the classroom? Child Care Health Dev 2010; 36: 455-64.

33 Galéra C, Melchior M, Chastang JF, Bouvard MP, Fombonne E. Childhood and adolescent hyperactivity-inattention symptoms and academic achievement 8 years later: the GAZEL Youth study. Psychol Med 2009; 39: 1895-906.

34 Scott S, Knapp M, Henderson J, Maughan B. Financial cost of social exclusion: follow up study of antisocial children into adulthood. BMJ 2001; 323: $191-4$.

35 Wolke D, Waylen A, Samara M, Steer C, Goodman R, Ford T, et al. Selective drop-out in longitudinal studies and non-biased prediction of behaviour disorders. Br J Psychiatry 2009; 195: 249-56.

36 Pingault JB, Tremblay RE, Vitaro F, Carbonneau R, Genolini C, Falissard B, et al. Childhood trajectories of inattention and hyperactivity and prediction of educational attainment in early adulthood: a 16-year longitudinal population-based study. Am J Psychiatry 2011; 168: 1164-70.

37 Rodriguez A, Jaervelin MR, Obel C, Taanila A, Miettunen J, Moilanen I, et al. Do inattention and hyperactivity symptoms equal scholastic impairment? Evidence from three European cohorts. BMC Public Health 2007; 7: 327.

38 Sayal K, Ford T Goodman R. Trends in recognition of and service use for attention-deficit hyperactivity disorder in Britain, 1999-2004. Psychiatr Serv 2010; 61: 803-10.

39 McGee R, Partridge F, Williams S, Silva PA. A twelve-year follow-up of preschool hyperactive children. J Am Acad Child Adolesc Psychiatry 1991; 30: 224-32.

40 Thorell LB. Do delay aversion and executive function deficits make distinct contributions to the functional impact of ADHD symptoms? A study of early academic skill deficits. J Child Psychol Psychiatry 2007; 48: 1061-70.

Neurobiological influences on suicide

\author{
Gustavo Turecki, Keith Hawton
}

Suicidal behaviour is a complex phenomenon that results from the interaction of different factors. Although the observation that propensity to suicide is hereditary dates back to the 18th century (Moore, 1790), only more recently have we begun to understand that genetic factors increase predisposition to suicidal behaviour, in part independently from psychopathology, and likely, by modifying at-risk behaviours such as impulsive-aggressive traits. Although precise neurobiological changes underlie the suicide process, we remain at the early stages of their identification. Studies suggest alterations in serotonin and other monoamines, and in neurotrophines and stress-response systems, such as the HPA and polyamines. 